Jurnal HELPER, Vol 36 No 2 (2019) 37 - 43

Bimbingan dan Konseling Universitas PGRI Adi Buana Surabaya

ISSN: 02162938

\title{
PEMBERDAYAAN MASYARAKAT MELALUI SENI GRAFIS (DESAIN KEMASAN PRODUK) HASIL OLAHAN BAHAN ALAM (KEARIFAN LOKAL) MASYARAKAT DESA BEGAGANLIMO, KECAMATAN GONDANG, KABUPATEN MOJOKERTO
}

\author{
Tantra Sakre \\ Program Studi Pendidikan Seni Rupa. Fakultas Keguruan dan Ilmu Pendidikan, \\ Universitas PGRI Adi Buana Surabaya \\ tantrasakre@unipasby.ac.id \\ Ismurdyahwati \\ Program Studi Pendidikan Seni Rupa. Fakultas Keguruan dan Ilmu Pendidikan, \\ Universitas PGRI Adi Buana Surabaya \\ ismurdyahwati@gmail.com
}

\begin{abstract}
Abstrak
Program kerja Nawacita yang digaungkan Joko Widodo, Presiden Republik Indonesia, dalam pidato pelantikannya pada tahun 2014 lalu memasukkan pembangunan dan pengembangan desa dan daerah terluar Indonesia sebagai salah satu sasaran utama program kerjanya (Halimah, 2017). Sejurus dengan itu, berangkat dari prinsip Trisakti oleh Bung Karno, beliau kembangkan pula cita-cita Bapak Pendiri Bangsa itu untuk mengembalikan kepribadian bangsa dalam kebudayaan (Soleman \& Noer, 2017). Desain grafis sebagai cabang dari batang kesenian pada pohon kebudayaan, bertansformasi dari sekedar wahana berekspresi seniman atau desainer menjadi sebuah alternatif jawaban bagi berbagai problematika pemasaran dan ekonomi. Desain kemasan yang baik dapat menaikkan nilai jual pada sebuah produk dalam persaingan pasar (Cenadi, 2004). Tujuan Program Pengabdian Masyarakat ini adalah untuk mengatasi masalah yang dijumpai di Desa Begaganlimo yaitu rendahnya pendapatan warga, rendahnya pengetahuan dan pemahaman mengenai pembuatan seni grafis (desain kemasan produk). Pelatihan ini dapat digunakan sebagai alternatif ketika menunggu hasil panen serta pemberian nilai tambah bagi produk lokal dengan hadirnya desain kemasan yang lebih menarik.
\end{abstract}

Kata Kunci: Pemberdayaan Masyarakat, Seni Grafis, Desain Kemasan Produk

\begin{abstract}
The Nawacita work program echoed by Joko Widodo, President of the Republic of Indonesia, in his inauguration speech in 2014 included the development and development of Indonesia's outer villages and regions as one of the main targets of his work program (Halimah, 2017). In line with that, departing from the Trisakti principle by Bung Karno, he also developed the ideals of the Founding Father of the Nation to restore the nation's personality in culture (Soleman \& Noer, 2017). Graphic design, as a branch of art in the tree of culture, is transformed from being just a vehicle for the expression of an artist or designer into an alternative answer to various marketing and economic problems. A good packaging design can increase the selling value of a product in market competition (Cenadi, 2004). The purpose of this Community Service Program is to overcome problems encountered in Begaganlimo Village, namely low income of residents, low knowledge and understanding of graphic art making (product packaging design). This training can be used as an
\end{abstract}


Jurnal HELPER, Vol 36 No 2 (2019) 37 - 43

Bimbingan dan Konseling Universitas PGRI Adi Buana Surabaya

ISSN: 02162938

alternative when waiting for the harvest as well as providing added value to local products with the presence of more attractive packaging designs.

Key Words: : Community Empowerment, Graphic Arts, Product Packaging Design

\section{LATAR BELAKANG}

Usaha Mikro, Kecil, dan Menengah (UMKM) merupakan salah satu sektor perekonomian yang diyakini dapat bertahan dalam menghadapi kondisi perekonomian global yang tidak menentu. Pentingnya peranan sektor ini telah menjadi perhatian khusus Presiden Joko Widodo-yang mana telah disusun dalam Program Nawacita, pada poin keenam perihal peningkatan produktivitas dan daya saing rakyat di pasar-dalam rangka mewujudkan kemandirian ekonomi. Karenanya, diperlukan berbagai upaya dengan pelibatan berbagai pihak untuk menggali potensi-potensi yang terdapat di masyarakat.

Sebagai upaya pengamalan Tri Dharma Perguruan Tinggi-utamanya berkaitan dengan pengabdian pada masyarakat—maka Tim Dosen Program Studi Pendidikan Seni Rupa Universitas PGRI Adi Buana Surabaya memiliki peran dan tanggung jawab untuk turut berpartisipasi dalam mewujudkan program Nawacita yang digagas oleh Presiden Joko Widodo. Pengamalan tersebut dalam hal ini berupa pelatihan dan pendampingan yang bertujuan mengembangkan potensi ekonomi suatu masyarakat daerah dengan mengarahkan Program Pengabdian Masyarakat ke daerahdaerah tertinggal.

Adapun wilayah dan sasaran kegiatan ini ialah masyarakat Desa Begaganlimo. Secara geografis, lokasi Desa Begaganlimo berada di kaki gunung Arjuno dan terletak di sisi sebelah selatan Kabupaten Mojokerto. Penduduk setempat mayoritas bermata pencaharian sebagai petani dan peternak. Desa Begaganlimo memiliki objek wisata yang baru-baru ini dikembangkan, yakni wisata Akar Seribu dan Air Terjun Tunjung Biru. Dua objek wisata tersebut ikut membantu menaikkan potensi wisata dan ekonomi setempat. Terdapat juga situs kuno berupa tumpukan lempengan batu berukuran besar yang terdapat di tebing aliran sungai, serta makanan khas Desa Begaganlimo yakni sego bumbungan, makanan yang menjadi bekal masyarakat ketika mencari nafkah di hutan.

Penelitian ilmiah telah membuktikan desain kemasan produk dapat meningkatkan nilai jual produk di pasaran. Salah satu bentuk paling sederhana dari bentuk kemasan modern saat ini adalah dengan proses sablon. Proses sablon dengan memberikan logo atau merek kepada kemasan memberikan penanda lebih pada produk lokal agar mampu bersaing dengan kompetitor. Derasnya arus persaingan usaha pada saat ini menyeret pegiat usaha untuk selalu memberikan nilai lebih ke produk mereka dan menonjol dalam peta persaingan produk-produk sejenis.

Menindaklanjuti uraian-uraian sebagaimana yang telah di kemukakan, maka 
Jurnal HELPER, Vol 36 No 2 (2019) 37 - 43

Bimbingan dan Konseling Universitas PGRI Adi Buana Surabaya

ISSN: 02162938

Tim Dosen Program Studi Pendidikan Seni Rupa Universitas PGRI Adi Buana Surabaya melakukan suatu kegiatan pengabdian pada masyarakat yang berjudul Pemberdayaan Masyarakat Melalui Seni Grafis (Desain Kemasan Produk) Hasil Olahan Bahan Alam (Kearifan Lokal) Masyarakat Desa Begaganlimo, Kecamatan Gondang, Kabupaten Mojokerto.

\section{Potensi Sumber Daya di Desa Begaganlimo}

\section{Kab. Mojokerto}

Desa Begaganlimo memiliki objek wisata yang baru-baru ini dikembangkan, yakni wisata Akar Seribu dan Air Terjun Tunjung Biru. Dua objek wisata tersebut ikut membantu menaikkan potensi wisata dan ekonomi setempat. Terdapat juga situs kuno berupa tumpukan lempengan batu berukuran besar yang terdapat di tebing aliran sungai, serta makanan khas Desa Begaganlimo yakni sego bumbungan, makanan yang menjadi bekal masyarakat ketika mencari nafkah di hutan.

Ramainya kunjungan oleh wisatawan yang berlibur di Akar Seribu dan Air Terjun Tunjung Biru memunculkan potensi ekonomi baru. Yakni banyaknya wisatawan yang ingin merasakan makanan khas setempat dan atau mencari produk kreatif untuk dijadikan oleholeh.

Karenanya berdasarkan silang forum yang telah dilaksanakan oleh Tim Dosen dengan masyarakat Desa Begaganlimo, diperoleh kesimpulan bahwa Desa Begaganlimo telah mempunyai beberapa produk lokal, hanya saja masih belum menggunakan kemasan produk yang menarik. Simpulan itu kemudian menjadi salah satu latar belakang pelaksanaan pengabdian masyarakat yang dilaksanakan oleh Tim Dosen Program Studi Pendidikan Seni Rupa Unipa Surabaya.

\section{Tujuan dan Manfaat Kegiatan Pengabdian}

\section{Pada Masyarakat}

Secara umum, program Pengabdian Pada Masyarakat (PPM) ini mempunyai tujuan dan kemanfaatan bagi masyarakat peserta PPM sebagai berikut:

1. Termanfaatkannya waktu senggang untuk menciptakan ekonomi kreatif seni grafis melalui sablon cetak saring.

2. Termanfaatkannya waktu senggang warga untuk memproduksi kemasan produk melalui seni grafis sablon cetak saring.

3. Tersedianya waktu senggang sembari menunggu hasil panen padi tiba, bisa dimanfaatkan untuk membuat kemasan produk hasil oalahan bahan alam melalui seni grafis sablon cetak saring.

4. Terjadinya peningkatan ekonomi warga melalui perkembangan usaha ekonomi kreatif yang diproduksi keluarga.

5. Meningkatkan partisipasi warga, bahwa Desa Begaganlimo sudah ada warga yang mampu memproduksi kemasan produk bahan olahan bahan alam melalui seni grafis sablon cetak saring, sehingga diharapkan mampu 
Jurnal HELPER, Vol 36 No 2 (2019) 37 - 43

Bimbingan dan Konseling Universitas PGRI Adi Buana Surabaya

ISSN: 02162938

meningkatkan daya saing lokal desa setempat.

\section{METODOLOGI}

\section{Perencanaan Kegiatan}

Pada tahapan ini, tim dosen mencari izin untuk melaksanakan Program Pengabdian Masyarakat pada Kepala Desa, mencari izin lokasi pelatihan dengan dibantu pertimbangan kepala desa setempat, dan menyiapkan bahan dan materi pelatihan. Observasi lapangan dilakukan pada tanggal 20 Agustus 2019. Suparman, S.Pd., M.Pd. beserta Herman Sugianto, S.Pd., M.Pd. menuju ke Desa Begaganlimo dan berkoordinasi dengan kepala desa setempat untuk menentukan kegiatan yang akan dilaksanakan berkaca dari skala kebutuhan desa yang bersangkutan.

Pada pertemuan tersebut ditentukan sarana dan prasarana apa saja yang hendaknya dipersiapkan oleh kedua belah pihak. Pihak Desa Begaganlimo mempersiapkan tempat pelatihan, mengumpulkan dan mengkoordinasikan peserta pelatihan yang terdiri dari pemuda Karang Taruna serta ibuibu PKK setempat. Sedangkan dari pihak Program Studi Pendidikan Seni Rupa mempersiapkan modul dan materi pelatihan.

\section{Pelaksanaan Kegiatan}

Pelaksanaan kegiatan Pengabdian Pada Masyarakat (PPM) oleh Tim Dosen Program Studi Pendidikan Seni Rupa Unipa Surabaya dilaksanakan dengan metode workshop atau loka karya. Workshop merupakan rangkaian kegiatan belajar atau pelatihan yang terarah dan terukur. Dalam pelaksanaanya, Tim Dosen tidak sekadar menyampaikan materi dengan cara presentasi, tetapi juga melakukan praktik bersama peserta kegiatan, serta memberi masukan dan evaluasi agar memeroleh hasil yang lebih baik atas kinerja pelatihan kepada peserta kegiatan.

Setelah melalui tahapan perencanaan (survei, penggalian potensi, proposal, perijinan, dan sosialisasi) dan penentuan metode pelaksanaan kegiatan, Tim Dosen menyusun jadwal kegiatan dan mempersiapkan materi pelatihan, serta prasarana yang dibutuhkan untuk mendukung keberlangsungan kegiatan. Adapun hal-hal mengenai tempat, peserta, dan pengkoordinasian peserta, telah dipersiapkan dengan baik oleh pihak Desa Begaganlimo.

Ada 3 materi yang dipersiapkan untuk dibagi kepada Karang Taruna dan warga Desa Begaganlimo, antara lain: 1). Pelatihan membuat konsep desain kemasan produk, 2). Pelatihan masyarakat untuk membuat film sablon cetak saring untuk kemasan produk berbagai media, dan 3). Pelatihan masyarakat untuk membuat kemasan produk berbagai media melalui seni grafis. Secara ringkas perihal kegiatan, materi pelatihan, dan pelaksana kegiatan dapat dilihat pada tabel berikut. 
Jurnal HELPER, Vol 36 No 2 (2019) 37 - 43

Bimbingan dan Konseling Universitas PGRI Adi Buana Surabaya

Tabel 1

\section{Kegiatan, Materi Pelatihan, dan Pelaksana Kegiatan}

\begin{tabular}{|c|c|c|c|c|}
\hline $\begin{array}{l}\mathbf{N} \\
\mathbf{0} \\
.\end{array}$ & Kegiatan & $\begin{array}{c}\text { Materi } \\
\text { Pelatiha } \\
\text { n }\end{array}$ & $\begin{array}{c}\text { Puk } \\
\text { ul }\end{array}$ & $\begin{array}{c}\text { Tim } \\
\text { Pelaksana }\end{array}$ \\
\hline 1 & $\begin{array}{l}\text { Pengenala } \\
\mathrm{n} \text { dan } \\
\text { Pembuatan } \\
\text { Desain } \\
\text { Kemasan }\end{array}$ & $\begin{array}{l}\text { Pelatihan } \\
\text { membuat } \\
\text { konsep } \\
\text { desain } \\
\text { kemasan } \\
\text { produk }\end{array}$ & $\begin{array}{l}08.0 \\
0- \\
10.0 \\
0 \\
\text { WIB }\end{array}$ & $\begin{array}{l}\text { 1. Dr. } \\
\text { Ismurdyah } \\
\text { wati, } \\
\text { M.Sn. } \\
\text { 2. Tantra } \\
\text { Sakre, } \\
\text { S.Sn., } \\
\text { M.Pd. }\end{array}$ \\
\hline 2 & $\begin{array}{l}\text { Proses } \\
\text { Pembuatan } \\
\text { Film }\end{array}$ & $\begin{array}{l}\text { Pelatihan } \\
\text { masyarak } \\
\text { at untuk } \\
\text { membuat } \\
\text { film } \\
\text { sablon } \\
\text { cetak } \\
\text { saring } \\
\text { untuk } \\
\text { kemasna } \\
\text { produk } \\
\text { berbagai } \\
\text { media }\end{array}$ & $\begin{array}{l}10.0 \\
0- \\
12.0 \\
0 \\
\text { WIB }\end{array}$ & $\begin{array}{l}\text { 1. } \\
\text { Supraman, } \\
\text { S.Pd., } \\
\text { M.Pd. } \\
\text { 2. Herman } \\
\text { Sugianto, } \\
\text { S.Pd., } \\
\text { M.Pd. }\end{array}$ \\
\hline 3 & $\begin{array}{l}\text { Pembuatan } \\
\text { Kemasan }\end{array}$ & $\begin{array}{l}\text { Pelatihan } \\
\text { masyarak } \\
\text { at untuk } \\
\text { membuat } \\
\text { kemasan } \\
\text { produk } \\
\text { berbagai } \\
\text { media } \\
\text { melalui } \\
\text { seni } \\
\text { grafis }\end{array}$ & $\begin{array}{l}12.3 \\
0- \\
14.3 \\
0 \\
\text { WIB }\end{array}$ & $\begin{array}{l}\text { 1. } \\
\text { Hariadie, } \\
\text { M.Pd. } \\
2 . \\
\text { Sepbianti } \\
\text { Rangga, } \\
\text { S.Pd., } \\
\text { M.Sn. }\end{array}$ \\
\hline
\end{tabular}

\section{HASIL PENELITIAN Uraian Kegiatan}

Kegiatan yang dilakukan yakni pengenalan dan pembuatan desain. Pada kegiatan ini, materi pelatihan yang disampaikan adalah pelatihan membuat konsep desain kemasan produk. Materi disampaikan oleh Dr. Ismurdyahwati, M.Sn. dan Tantra Sakre, S.Sn., M.Pd. di Balai Desa Begaganlimo pada pukul 08.00-10.00 WIB. Setiap materi yang disampaikan memiliki durasi waktu selama dua jam, yang diisi dengan penyampaian materi, praktik, penugasan, serta tanya jawab.

Pada tahap pertama, Dr. Ismurdyahwati, M.Sn., menyampaikan hal-hal apa saja yang perlu diperhatikan dalam membuat konsep desain untuk kemasan produk. Pemateri menyampaikannya melalui power point, agar lebih efektif dan dapat menarik minat peserta. Adapun durasi yang ditempuh pada tahap ini adalah 30 menit.

Pada tahap kedua, Tantra Sakre, S.Sn., M.Pd., mempraktikkan serta menambahi halhal yang telah disampaikan oleh pemateri pertama. Pemateri kedua mempraktikkannya dengan menggunakan peralatan yang telah dipersiapkan sebelumnya, sementara peserta pelatihan menyaksikannya. Adapun durasi yang ditempuh pada tahap ini adalah 30 menit.

Pada tahap ketiga, peserta pelatihan diberi tugas untuk membuat konsep desain. Pada tahap ini pemateri pertama dan pemateri kedua juga mendampingi peserta, terutama ketika peserta masih menemukan kesulitan dalam membuat konsep. Adapun durasi yang ditempuh pada tahap ini adalah 40 menit.

Pada sesi tanya jawab, terdapat sejumlah pertanyaan yang diajukan oleh 
Jurnal HELPER, Vol 36 No 2 (2019) 37 - 43

Bimbingan dan Konseling Universitas PGRI Adi Buana Surabaya

ISSN: 02162938

peserta pelatihan untuk kemudian ditanggapi oleh pemateri pertama dan pemtarei kedua. Pada sesi ini durasi waktu tanya jawab dibatasi selama 20 menit, sehingga kegiatan pelatihan ini berakhir pada pukul 10.00 WIB.

\section{Evaluasi Kegiatan}

Tahapan evaluasi dilaksanakan setelah Tim Dosen melaksanakan Program Pengabdian Masyarakat. Pada setiap tahapan pelaksanaan, tim dosen melakukan evaluasi. Poin-poin yang dievaluasi dimulai dari tahap perencanaan sampai ketika pelaksanaan program. Ditemukan beberapa hal yang menarik selama kegiatan Pengabdian Masyarakat ini, mulai dari kesusahan mencari lokasi, antusias ibu-ibu peserta kegiatan yang melebihi pemuda karang taruna, sampai ajakan jalan-jalan oleh kepala desa ke kebun durian beliau.

\section{KESIMPULAN}

Banyak wisatawan yang berkunjung ke Akar Seribu dan Air Terjun Tunjung Biru yang berada di Desa Begaganlimo, kemudian mencari oleh-oleh atau cinderamata. Akan tetapi, beberapa produk lokal Desa Begaganlimo belum menggunakan kemasan produk yang menarik. Berdasarkan hal tersebut, Tim Dosen Program Studi Pendidikan Seni Rupa Universitas PGRI Adi Buana Surabaya melakukan pemberdayaan masyarakat melalui seni grafis (desain kemasan produk) hasil olahan bahan alam (kearifan lokal) masyarakat Desa Begaganlimo, Kecamatan Gondang, Kabupaten Mojokerto.
Adapun materi yang disampaikan Tim Dosen Program Studi Pendidikan Seni Rupa Unipa Surabaya, meliputi: 1). Pelatihan membuat konsep desain kemasan produk, 2). Pelatihan masyarakat untuk membuat film sablon cetak saring untuk kemasan produk berbagai media, dan 3). Pelatihan masyarakat untuk membuat kemasan produk berbagai media melalui seni grafis.

Pada akhirnya, kegiatan ini dapat memanfaatkan waktu senggang yang dimiliki oleh masyarakat Desa Begaganlimo untuk menciptakan ekonomi kreatif. Hal ini mengingat potensi yang muncul melalui kunjungan wisatawan yang banyak, yang mana materi pelatihan yang disampaikan dapat secara langsung akan meningkatkan perekonomian masyarakat.

\section{Saran}

Kegiatan Pengabdian Pada Masyarakat yang dilakukan oleh Tim Dosen Program Studi Pendidikan Seni Rupa Universitas PGRI Adi Buana Surabaya ini merupakan langkah dasar. Karenanya sebagai saran, diharapkan nantinya diadakan kegiatan yang serupa tetapi dengan materi yang berkelanjutan dari materi dasar ini.

\section{DAFTAR PUSTAKA}

Cenadi, C. S. (2004). Peranan desain kemasan dalam dunia pemasaran. Nirmana, 2(2).

Halimah, F. (2017). Studi Deskriptif Penerapan Program Nawacita Presiden 
Jurnal HELPER, Vol 36 No 2 (2019) 37 - 43

Bimbingan dan Konseling Universitas PGRI Adi Buana Surabaya

ISSN: 02162938

Joko Widodo Tentang Membangun

Indonesia Dari Pinggiran Terhadap

Kesejahteraan Warga Di Desa Kanoman

Kecamatan Panjatan Kabupaten Kulon

Progo. Prodi PPKn Universitas PGRI

Yogyakarta.

Soleman, M., \& Noer, M. (2017). Nawacita

Sebagai Strategi Khusus Jokowi Periode

Oktober 2014-20 Oktober 2015.

POLITIK, 13(1). 